\title{
Erratum
}

\section{Feline penile erections induced by topical glans penis application of combination alprostadil and SEPA (Topiglan)}

MF Usta, J Sanabria, TJ Bivalacqua and WJG Hellstrom

International Journal of Impotence Research (2004) 16, 303. doi:10.1038/sj.ijir.3901229

Correction to: International Journal of Impotence Research (2004) 16, 73-77. doi:10.1038/sj.ijir.3901145

Due to a typesetting error, one of the authors' names was spelled incorrectly. The correct spelling is 'Jose Sanabria.' 